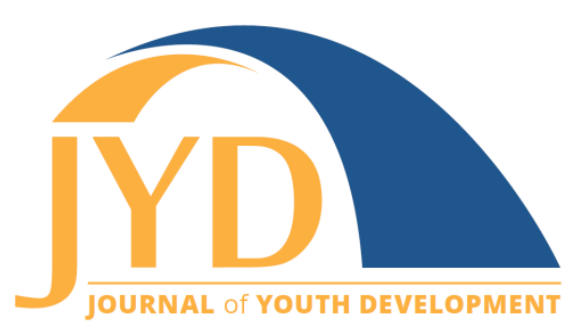

http://jyd.pitt.edu/ | Vol. 16 Issue 2-3 DOI 10.5195/jyd.2021.1020 | ISSN 2325-4017 (online)

\title{
Resilience-Informed Positive Youth Development Programs in International Development
}

\author{
Nalini Bajaj Chugani \\ Education Development Center \\ nchugani@edc.org \\ Sabeen Faizullah \\ Education Development Center \\ sfaizullah@edc.org

\section{Cornelia Janke} \\ Education Development Center \\ cjanke@edc.org \\ Rebecca Jeudin \\ RTI International \\ rjeudin@rti.org

\section{Jackie Kiernan} \\ Education Development Center \\ jkiernan@edc.org

\section{Nancy Wallace} \\ Education Development Center \\ nwallace@edc.org
}

\begin{abstract}
In countries affected by crisis and conflict, systems that support young people are often disrupted. Youth who are going through critical periods of physical, cognitive, and social-emotional development are especially affected by these disruptions. We examined positive youth development programming strategies that have been used in crisis and conflict-affected areas to build youth resilience, defined as a young person's ability to manage risk (absorptive capacity), enhance assets and agency (adaptive capacity), and contribute to society (transformative capacity). We summarize key concepts of positive youth development and resilience and then examine how these have been interpreted and applied in youth development programming. We present 2 case studies of youth programs from the Philippines and
\end{abstract}

(c) EY New articles in this journal are licensed under a Creative Commons Attribution 4.0 License. This journal is published by the University Library System, University of Pittsburgh and is cosponsored by the University of Pittsburgh Press. The Journal of Youth Development is the official peer-reviewed publication of the National Association of Extension 4-H Youth Development Professionals and the National AfterSchool Association. 


\section{Resilience-Informed Positive Youth Development}

the Democratic Republic of Congo that illustrate programming that integrates these concepts and discuss how resilience and positive youth development can intersect and reinforce one another. Using empirical findings from these crisis and conflict-affected settings, we illustrate how resilience-informed positive youth development programming builds youth and community assets and agency while increasing the absorptive, adaptive, and transformative resilience capacities of both youth and their communities to respond to shocks and stressors. We conclude with a discussion of relevant takeaways and program implications regarding the application of a resilience lens to positive youth development, particularly in areas affected by crisis or conflict.

Key words: positive youth development; absorb, adapt, transform; resilience capacities; crisis and conflict

\section{Introduction}

Globally, more than 400 million youth (ages 15 to 29) are living in crisis and conflict-affected settings (Simpson, 2018). In these contexts, traditional support systems for young people are often disrupted: families are uprooted or separated, trusted community networks are broken, and the state is unable to assume its responsibility to provide basic services and social safety nets. Youth in critical stages of physical, cognitive, and social-emotional development are especially affected by these disruptions (Kadir et al., 2018). We are thus prompted to consider whether and how positive youth development (PYD) programming can offer appropriate supports to enable youth, especially those most vulnerable, to be resilient in the face of these challenges.

We begin with a summary of key concepts and an overview of the traditional application of PYD and resilience, followed by two case studies. For the case studies, we selected two youth projects funded by the U.S. Agency for International Development (USAID) that focused on resilience and aligned with USAID's PYD Framework: the Mindanao Youth for Development (MYDev) program in the Philippines and the Integrated Youth Development Activity (IYDA) project in the Democratic Republic of Congo (DRC). Using empirical findings from these conflictaffected settings, we illustrate how resilience-informed PYD builds youth and community assets and agency in the face of shocks and stressors. Our findings suggest that the explicit addition of a resilience focus to PYD programs strengthens an individual's ability to cope and adapt and opens up entry points for community and systemic recovery and growth. We conclude with a discussion of relevant takeaways and implications regarding the application of resilienceinformed PYD in crisis and conflict-affected contexts. 


\section{Resilience-Informed Positive Youth Development}

\section{Foundational Concepts}

Positive youth development has been a mainstay of U.S.-based youth engagement since the 1990s, gaining traction over the past decade in the international development arena (Alvarado et al., 2017). While there are several well-regarded PYD frameworks (e.g., 4-H Program, Community Action Framework, Development Assets Framework, Five C's), they share a common philosophy that youth are valuable assets rather than burdens to society and must be engaged to benefit their communities.

USAID defines PYD as an approach that "engages youth along with their families, communities, and/or governments to empower youth to reach their full potential and build skills, assets, and competencies; foster healthy relationships; strengthen the environment; and transform systems" (YouthPower, n.d.-b, para. 3). PYD is meant to develop and support the assets, agency, contributions, and enabling environment of healthy, productive, and engaged youth, in both development contexts and emergencies (YouthPower, n.d.-a). Moreover, it is important to note that PYD is exclusively youth-focused and can be leveraged in both humanitarian and development contexts.

We define resilience as the ability of individuals, households, communities, or systemsparticularly in crisis or conflict-affected contexts-to reduce or manage risk (absorptive capacity), enhance assets and agency (adaptive capacity), and contribute to society (transformative capacity) (Béné et al., 2012; USAID, 2012) in response to acute shocks or longterm stresses. The initial absorptive or coping response is "re-active"-it restores status to the pre-adversity state. In the adaptive step, we proactively learn from past experiences to anticipate future risk and adjust accordingly. While absorption happens in the immediate to short term, adaptation requires both time and intention to change. Finally, transformation includes the intent to fundamentally alter status so that the individual, family, community, and/or system is better off than it was before the adversity took place (Keck \& Sakdapolrak, 2013).

Resilience can refer to individual, community, and system-level responses; the term is used by various disciplines, including ecology, engineering, psychology, and disaster preparedness. In this paper, we refer primarily to its application in the latter two disciplines, with the psychological domain being most applicable to PYD. Psychological resilience theory is relevant for all age groups. It uses a socio-ecological model (Bronfenbrenner, 1977) that recognizes the influence external factors might have on any given individual at the family, 


\section{Resilience-Informed Positive Youth Development}

community/organizational, and societal/systemic level. Because these factors interact to influence an individual's resilience and to affect their interactions with family, community, and institutional systems, efforts to promote resilience require multi-pronged approaches (Lerner, 2006; Panter-Brick \& Eggerman, 2012; Ungar, 2013). The PYD framework can also be viewed as working across the family, community/organizational, and societal/systemic levels, as Jessee et al. (2019) demonstrated. Thus, we argue that resilience-informed PYD can simultaneously support individuals and build community and systemic resilience, as part of both emergency preparedness and responsive programming (Masten, 2014).

\section{Programmatic Applications: Strengthening the Resilience Focus of Positive Youth Development}

Increasingly, international organizations have determined that a resilience-oriented approach informs programming across the individual, community, and systems levels, from both a proactive prevention perspective that tackles root causes and an adaptive perspective that breaks cycles of stunted development and negative coping behaviors (McCandless \& Simpson, 2015; Shah, 2019). Therefore, the incentive for PYD programming to be resilience-oriented is rooted in the reality that crisis and conflict are complex and last on average more than 9 years (EU Science Hub, 2020). In such a setting, youth can benefit from a resilience-informed PYD approach that empowers them to leverage their core assets in addressing ongoing challenges, cope with instability in healthier ways through social and emotional supports, and build toward a future that they have a key role in shaping with stronger functional competencies and technical skills.

Masten (2014) acknowledged that "the assets highlighted by PYD bear a striking resemblance to ... promotive and protective factors repeatedly observed in studies of resilience in young people (Masten, 2013, 2014b)" (p. 1020). In this paper we suggest that a resilience-informed PYD approach blends youth-centric orientation with recognition that contextual adversities deeply affect individual, community and societal well-being. Specifically, this approach sequences youth-focused and youth-led interventions in a way that enhances individual and community response and recovery and mitigates cycles of violence and poverty, ultimately through learning, civic engagement, and livelihood opportunities. (See Table 1.) 
Resilience-Informed Positive Youth Development

Table 1. Where PYD Domains and Resilience Capacities Intersect at the Individual Level

\begin{tabular}{|c|c|c|c|}
\hline \multirow[t]{2}{*}{ PYD Pillar } & \multicolumn{3}{|c|}{ Resilience Capacities } \\
\hline & $\begin{array}{l}\text { Absorptive } \\
\text { We want youth, communities, and } \\
\text { systems to be able to absorb shocks } \\
\text { and stressors (reactive coping). }\end{array}$ & $\begin{array}{l}\text { Adaptive } \\
\text { In order to adapt, a young person must be able to } \\
\text { recognize the shock or stressor and make an } \\
\text { intentional decision on how to prepare for and } \\
\text { respond to it, using a wider array of social safety } \\
\text { nets that are built over time (proactive learning } \\
\text { from past experiences to anticipate and plan for } \\
\text { future risk). }\end{array}$ & $\begin{array}{l}\text { Transformative } \\
\text { Transformative capacity is built over time and } \\
\text { characterizes the stage when one is inspired to propel } \\
\text { change-at the individual, community, or systems } \\
\text { level-to reduce the risks and decrease the effect of } \\
\text { known threats to well-being (intent to fundamentally } \\
\text { alter status so that the individual, community or system } \\
\text { is better off than it was before the adversity took place). }\end{array}$ \\
\hline $\begin{array}{l}\text { Assets } \\
\text { Literacy, numeracy, life } \\
\text { skills, access to financing, } \\
\text { SEL, self-control }\end{array}$ & $\begin{array}{l}\text { Accelerated Learning Programs- } \\
\text { access, upgraded curriculum, } \\
\text { professional development for } \\
\text { teachers } \\
\text { - Basic soft skills, including } \\
\text { communication and teamwork }\end{array}$ & $\begin{array}{l}\text { - Participation in savings and loans groups to } \\
\text { access savings and loans mechanisms } \\
\text { - Technical and vocational skills and training } \\
\text { - Foundations of Resilience training }\end{array}$ & \\
\hline $\begin{array}{l}\text { Agency } \\
\text { Goal-setting, planning } \\
\text { ahead, positive self- } \\
\text { awareness, perseverance }\end{array}$ & & $\begin{array}{l}\text { - Advanced soft skills, including creating } \\
\text { personal development plans, communicating } \\
\text { in the workplace, preparing for a job, and } \\
\text { leadership } \\
\text { - Entrepreneurship training, micro-enterprise } \\
\text { planning, and financial management } \\
\text { - Life skills (individual youth resilience-building } \\
\text { curriculum) } \\
\text { - Advanced leadership training for Youth } \\
\text { Network leaders }\end{array}$ & $\begin{array}{l}\text { Work-based Learning (in-person and virtual): } \\
\text { structured activities that provide guided access to } \\
\text { livelihood opportunities and debrief to build } \\
\text { agency. }\end{array}$ \\
\hline
\end{tabular}


Table 1. (continued)

\begin{tabular}{|c|c|c|c|}
\hline \multirow[t]{2}{*}{ PYD Pillar } & \multicolumn{3}{|c|}{ Resilience Capacities } \\
\hline & Absorptive & Adaptive & Transformative \\
\hline $\begin{array}{l}\text { Contribution } \\
\text { Civic and youth } \\
\text { engagement }\end{array}$ & & $\begin{array}{l}\text { - Youth efforts to build peer networks } \\
\text { community service learning - through } \\
\text { community contributions }\end{array}$ & $\begin{array}{l}\text { - Building microfinance networks } \\
\text { - Youth (peer-to-peer) networks } \\
\text { - Youth-led community activities conducted by } \\
\text { youth-serving community-based organizations or } \\
\text { YDAs } \\
\text { - Youth-led resilience projects } \\
\text { - Youth development alliances (YDAs): Multi- } \\
\text { stakeholder representative bodies }\end{array}$ \\
\hline $\begin{array}{l}\text { Enabling Environment } \\
\text { Including social, } \\
\text { normative, structural, and } \\
\text { physical supports } \\
\text { (YouthPower, n.d.-a) }\end{array}$ & \multicolumn{3}{|c|}{$\begin{array}{l}\text { - Social supports: Relationships with peers and adults (e.g., healthy relationships and bonding, building resilience and healthy coping skills, } \\
\text { mentoring and volunteer literacy networks) } \\
\text { - Normative supports: Attitudes, norms and beliefs (e.g., positive norms, expectations, and perceptions) } \\
\text { - Structural supports: Laws, policies, programs, services, and systems (e.g., youth-friendly local government forums) } \\
\text { - Physical supports: Safe, supportive spaces (e.g., access to age-appropriate and youth-friendly services) }\end{array}$} \\
\hline
\end{tabular}




\section{Resilience-Informed Positive Youth Development}

Recognizing that our understanding of resilience uses Bronfenbrenner's socio-ecological model, Table 1 outlines how resilience aligns with PYD, honing in on the individual.

At the individual level, where PYD programming may focus on strengthening youth assets and agency, the entry points can include resources for individuals that build social-emotional learning, interpersonal skills, and life skills-such as communication, critical thinking, and relationship development-and building agency through better decision-making, meaningmaking, and self-efficacy.

The next level of entry points, and the one with the most immediate opportunities to effect positive change at scale, is through building community resilience capacities. By partnering with community organizations or child protection actors, PYD programming can enhance individuals' assets and agency while also strengthening organizations or communities through absorptive, adaptive, and at times even transformative capacity building (i.e., strengthening resilience). Communities also benefit from engaged, empowered youth, who in turn are then better connected to social networks that meaningfully contribute to the collective community good.

At the larger systems level, PYD is concerned with youth interactions with the enabling environment; here, systemic resilience can be strengthened through entry points that may be long-standing and/or large-scale (or small, time-sensitive, and immediate) and serve to unite (rather than divide) or include (rather than exclude) diverse groups within a population. Potential entry points include youth leadership opportunities within programs, national or regional policies and laws enacted to promote youth participation, service delivery provisions actualized to support youth development outcomes, and-as the two case studies will highlight-entities established or re-formed, such as youth development alliances (YDAs). This diversity of entry points illustrates the massive potential of systemic-level interventions to transform resilience capabilities, thus building enabling environments for youth.

When PYD and resilience are mapped across the socio-ecological levels (as shown in Figure 1), we can identify specific entry points or activities within the PYD framework that reinforce one or more resilience capacities. 
Figure 1. Resilience-Informed Positive Youth Development Programs Within a Socio-Ecological Model

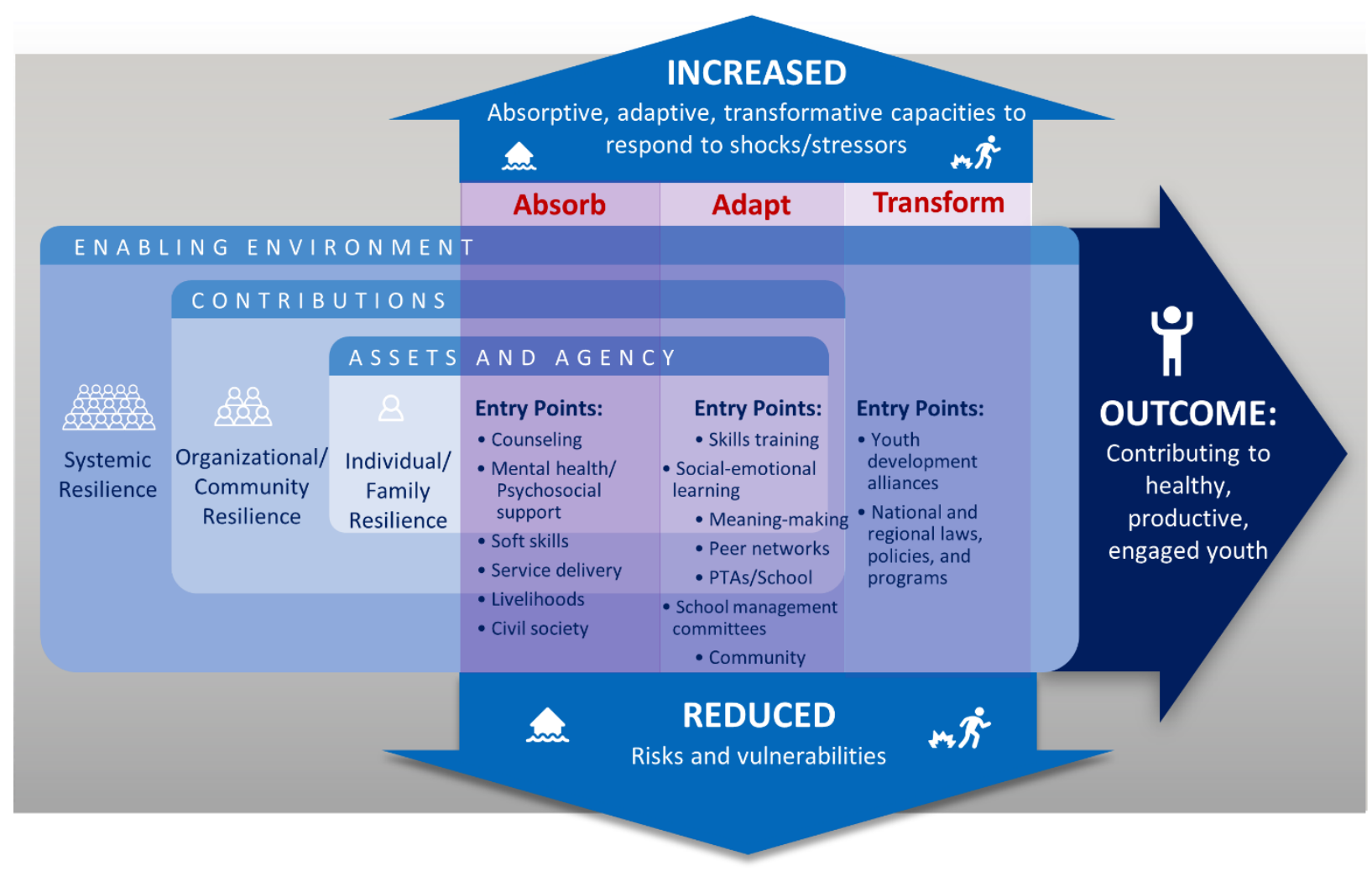

Resilience capacities across socio-ecological levels are interrelated; therefore, youth programming often works best when it operates across multiple levels (individual, community, and systems) to facilitate the interrelated aspects of PYD and resilience building.

\section{Methodology for Case Study Findings}

To demonstrate the impact of using a resilience-informed PYD approach, we present and discuss findings from evaluation studies conducted by the MYDev program in the Philippines and the IYDA project in the Democratic Republic of Congo. MYDev and IYDA both designed and implemented quasi-experimental evaluation studies to examine their contributions to changes in youth resilience; in both cases, data indicated increased resilience across the individual, community, and systems levels. The case studies are summarized in Table 2. 
Table 2. MYDev and IYDA Case Studies at a Glance

\begin{tabular}{|c|c|c|c|c|}
\hline $\begin{array}{l}\text { Project and } \\
\text { timeframe }\end{array}$ & Interventions & Type of study & Sample size & Tools \\
\hline $\begin{array}{l}\text { MYDev } \\
(2013-2017)\end{array}$ & $\begin{array}{l}100 \text { hours of life skills } \\
\text { training } \\
\text { - } 3 \text { weeks to } 9 \text { months of } \\
\text { technical/vocational skills } \\
\text { education and training } \\
\text { (TVET) or basic education } \\
\text { - Post-training support } \\
\text { - Youth Network formation } \\
\text { - Youth Development Alliance } \\
\text { establishment }\end{array}$ & $\begin{array}{l}\text { Quasi-experimental } \\
\text { evaluation (baseline } \\
\text { and endline) }\end{array}$ & $\begin{array}{l}1,657 \text { intervention } \\
\text { youth and } 401 \\
\text { control youth; all } \\
\text { youth were } \\
\text { randomly selected }\end{array}$ & $\begin{array}{l}\text { - Youth Perceptions } \\
\text { Survey (YPS) } \\
\text { - Youth Employment } \\
\text { Survey (YES) }\end{array}$ \\
\hline $\begin{array}{l}\text { MYDev } \\
\text { extension } \\
\text { quasi- } \\
\text { experimenta } \\
\text { I study } \\
(2018-2019)\end{array}$ & +22 hour resilience training & $\begin{array}{l}\text { MYDev } \\
\text { performance } \\
\text { evaluation (no } \\
\text { control group; } \\
\text { baseline and } \\
\text { endline) }\end{array}$ & $\begin{array}{l}\text { Proportional } \\
\text { stratified random } \\
\text { sample by sex and } \\
\text { location of } 789 \\
\text { program youth }\end{array}$ & $\begin{array}{l}\text { YPS+ (original survey } \\
\text { with additional questions } \\
\text { on youth perceptions of } \\
\text { violence and personal } \\
\text { resilience skills) }\end{array}$ \\
\hline $\begin{array}{l}\text { MYDev } \\
\text { extension } \\
\text { performance } \\
\text { evaluation } \\
\text { study (2018- } \\
\text { 2019) }\end{array}$ & & $\begin{array}{l}\text { Outcome harvest } \\
\text { study }\end{array}$ & & $\begin{array}{ll}\text { - } & \text { Document review } \\
\text { - } & \text { Focus group } \\
\text { discussions } \\
\text { - } \\
\text { Key informant } \\
\text { interviews }\end{array}$ \\
\hline $\begin{array}{l}\text { IYDA DRC } \\
(2018-2021)\end{array}$ & $\begin{array}{l}\text { - Numeracy and literacy (1 } \\
\text { academic school year or } \\
\text { training cycle) } \\
\text { - Life skills training (43-80 } \\
\text { hours) } \\
\text { - Post-training support (1 } \\
\text { session/week for } 3 \text { months) } \\
\text { - YDA establishment }\end{array}$ & $\begin{array}{l}\text { Single group } \\
\text { pretest-posttest } \\
\text { quasi-experimental } \\
\text { design assessing a } \\
\text { sample group of } \\
\text { participants } \\
\text { longitudinally at } \\
\text { baseline, midline, } \\
\text { and endline }\end{array}$ & $\begin{array}{l}\text { Clustered sample by } \\
\text { school type and } \\
\text { location, } 1,143 \\
\text { youth ( } 770 \text { youth in } \\
\text { Accelerated } \\
\text { Learning Programs } \\
\text { (ALP), } 373 \text { youth in } \\
\text { TVET) }\end{array}$ & $\begin{array}{l}\text { - YES } \\
\text { - YPS adapted with } \\
\text { PYD International } \\
\text { Youth Development } \\
\text { Survey subscales on } \\
\text { optimism, positive } \\
\text { identity, support, and } \\
\text { prosocial norms }\end{array}$ \\
\hline
\end{tabular}




\section{Resilience-Informed Positive Youth Development}

\section{Theory of Change: MYDev and IYDA}

The overall theory of change for both projects is that, in fragile contexts:

If youth gain relevant emotional, foundational, and livelihoods skills and have community opportunities to contribute to society through social and civic engagement, then they are better able to prevent, respond to, and mitigate the impact of protracted and rapid-onset crises and to contribute positively to family and community resilience.

\section{MYDev Research Methodology}

To measure youth outcomes, the program implemented three studies (quasi-experimental, performance evaluation, and outcome harvest study), using context-specific tools validated by key youth stakeholders. For the quasi-experimental study, the program adapted and implemented the Youth Employment Survey (YES) to collect data on elements that characterize youth employment and underemployment in both the formal and informal sectors. To complement this, MYDev designed and implemented the Youth Perceptions Survey (YPS) to measure youths' perceptions of their community and government. All tools were developed, adapted, and validated in the Philippines.

In the final year of the program, MYDev introduced an enhanced training intervention focused on resilience, accompanied by a performance evaluation suitable for the program timeline and new additions (activities as well as implementation sites). As part of the performance evaluation, MYDev adapted the YPS to measure youths' perceptions of violence and their own personal resilience skills by adding questions on these topics. The adapted YPS+ was better able to estimate the effect of the enhanced program interventions. This included questions on youth perceptions of violence and personal resilience skills to estimate the effect of the enhanced project interventions.

The program also conducted a modified outcome harvest study, adapting the original outcome harvesting model developed by Wilson-Grau and Britt (2012), to look retrospectively at outcomes related to youth's resilience to violence, using data from all MYDev program sites across the 6-year program. This study answered the question, What outcomes reflect youth's resilience to violence, and to what extent did MYDev program elements contribute to these outcomes? The study included a review of internal and external documents, followed by focus group discussions and key informant interviews. The final step was outcome substantiation. 


\section{Resilience-Informed Positive Youth Development}

Participants included youth and their immediate and extended family members, friends, and neighbors.

\section{IYDA Research Methodology}

IYDA designed and implemented a single group pretest-posttest quasi-experimental evaluation in an effort to better understand the project's contribution to changes in youth resilience. IYDA used a clustered sample approach (by school type and location) to select a representative sample: 1,160 participants were sampled, with 1,143 validated observations for analysis. A total of 770 youth from 42 Level 3 (Grades 5 and 6) Accelerated Learning Programs (ALP) and 373 youth from 22 professional training centers participated (EDC, 2020, p.10).

Youth sampled were assessed longitudinally at three points: during enrollment, pre-intervention (baseline); at the conclusion of training (midline) to measure changes in knowledge, attitudes, and skills; and 4 to 6 months after graduation (endline) to measure changes in assets, practices, and resilience. IYDA used the YPS as well as components from the PYD International Youth Development Survey (specifically, the subscales on optimism, positive identity, support, and prosocial norms ) to measure changes in youth perceptions. The YES, and the Big Five Inventory $^{1}$ tools were also utilized. (EDC, 2020, p.8-9)The quasi-experimental design selected for IYDA is considered technically sound. However, as this approach does not have a counterfactual to represent what youth outcomes might have been without the intervention, the results can only suggest the influence of the project's interventions on IYDA youth, without claims of causality.

\section{MYDev Case Study}

MYDev (2013-2019) was a PYD education program focused on employment outcomes, community engagement, and strengthening local capacity to deliver education and employment services to youth. Participants mostly comprised those impacted by decades of protracted conflict in the southern Philippines, which had strained and weakened the social contract among youth and their local communities. The program provided life skills training (100 hours) and basic education (800+ hours) or technical skills training (1 to 9 months). Post-training support, including youth network formation and youth-led activities, was ongoing through the life of the

\footnotetext{
${ }^{1}$ The Big Five Inventory measures conscientiousness (work ethic, organization), agreeableness (kindness, empathy), emotional stability (composure, flexibility), openness (curiosity, analytical thinking), and extraversion (sociability, assertiveness).
} 


\section{Resilience-Informed Positive Youth Development}

program. The program also built the capacity of local government units, communities, and stakeholders through the establishment and strengthening of YDAs.

\section{Results: Quasi-Experimental Findings (2017)}

The YPS revealed that at baseline MYDev and non-MYDev youth had significantly different perceptions of their communities, with comparison youth scoring higher, reflecting more positive ratings $(p<.01)$. However, at endline, MYDev youth's scores increased substantially to an average score of 3.44, and comparison youth's scores decreased slightly to an average score of 3.18; there is a statistically significant difference between comparison and intervention group youth $(p<.01)$ (Education Development Center, Inc. [EDC], 2019b, p. 14).

Likewise, MYDev's programming appears to have had a significant effect on youth perceptions of the government. At baseline, there was no significant difference in the intervention and comparison group; however, at endline, MYDev youth's government perception scores were significantly higher than those of non-MYDev youth (3.27 vs. 3.01, respectively) $(p<.01)$ (EDC, 2019b, p. 23).

The YES study revealed that MYDev youth demonstrated significantly higher rates of employment gains relative to youth who did not participate in the program. MYDev youth seemed to have greater improvements in their life, work readiness, and leadership skills from baseline to endline than non-MYDev youth: 73\% of MYDev youth improved either their life skills, work readiness skills, or leadership skills between baseline and endline, compared to $63 \%$ of non-MYDev youth $(p<.001)$. Additionally, MYDev youth improved their skills to a greater extent (EDC, 2019b, p. 10).

\section{Performance Evaluation (2018-2019)}

The YPS+ (which included youths' perceptions of their own resilience and perceptions toward violence) demonstrated that $58 \%$ of MYDev youth showed positive changes in their perceptions of violence, including violent extremism-meaning that they moved toward supporting nonviolent or peaceful conflict resolution over violent actions. Moreover, 55\% of MYDev youth demonstrated improved resilience skills ${ }^{2}$ from baseline to endline, reflecting increased confidence levels in their own abilities-their agency (EDC, 2019b, p. 17).

\footnotetext{
${ }^{2}$ For the purpose of this study, resilience skills were defined as the ability to think of consequences to oneself and others, talk through a disagreement, calm down when mad, understand another's point of view, and stay out of fights.
} 


\section{Resilience-Informed Positive Youth Development}

At endline, MYDev youth reported significantly higher confidence in their ability to behave in nonviolent ways. The greatest change was in response to the prompt "I can stay out of fights," with an additional $12 \%$ of program youth responding that they are either somewhat or very confident that they can stay out of fights. At endline, youth were most confident in their ability to "talk out a disagreement," with $85 \%$ of youth stating that they were either somewhat or very confident that they could do this (EDC, 2019b).

\section{Outcome Harvest Study}

During the outcome harvest study, youth shared that prior to the MYDev program, they often responded with violence when they felt hurt, insulted, or discriminated against. After participating in MYDev, a majority of the youth clearly articulated a change in their behavior, from reacting quickly and violently to considering the consequences of their actions and reacting less. During the substantiation phase of data collection, respondents related to MYDev youth were better able to corroborate these changes than the respondents not related to MYDev youth. As one mother of a MYDev youth said, "She has more control of her emotions. Things in our family have become better. It helps because she is no longer hot-tempered. Now we can talk things through" (EDC, 2019c, p. 18). MYDev youth alumni are able to consider the consequences of their actions and manage their anger and emotions.

\section{Discussion}

MYDev's focus on PYD assets provides youth with basic foundational life skills training, thus supporting youth and community leaders in better managing emerging conflicts through such skills as communication, critical thinking, and leadership. These competencies effectively help youth absorb shocks and stressors linked to tensions and actual crisis and conflict. The program's life skills curriculum is grounded in agency and contribution, by fostering a positive self-concept, providing guidance on setting and achieving goals, and supporting a positive perception of community and government, which contributed to youth and communities' adaptive capacities to navigate a volatile context.

When the Marawi Siege broke out in May 2017, displacing more than 300,000 people (including MYDev youth and their families), youth experienced acute needs related to the violence they witnessed. Further, the siege led to a notable increase in pressure from various violent extremist groups (Casey \& Pottebaum, 2017). As such, MYDev expanded its life skills curriculum package by adding Foundations of Resilience training modules. These modules, grounded in evidence-based cognitive-behavioral approaches, are designed to provide youth with strategies 


\section{Resilience-Informed Positive Youth Development}

to process conflict in general and violent extremist actions in particular. Part 1 of the training aimed to help youth understand the connections between their thoughts, feelings, and behaviors, thus building their coping and interpersonal communication skills. Part 2 aimed to help youth understand violent extremism in the local context of Mindanao and provided coping strategies, including strengthening their social support system, reducing stigma, and building awareness of their own vulnerabilities to violence and violent extremism. The integration of these modules helped youth expand their protective factors, including good mental health practices, critical-thinking skills, and positive coping mechanisms.

Integrating a resilience focus into the promotion and development of assets and agency at the individual level set the stage for MYDev youth to contribute to community resilience. As part of the life skills training, youth were required to participate in youth-led community service activities and resilience projects, Youth were able to recognize the recent trauma in their community and make an intentional decision to respond to, anticipate, and plan for future risk. In the aftermath of the Marawi Siege, youth became agents who fostered community resilience and cohesion, thus enhancing the social contract between youth and their family, community, and government.

Further, the MYDev outcome harvest study (EDC, 2019c) revealed that when personally confronted with a violent or potentially violent situation, MYDev youth were able to absorb the shock and adapt their response in order to avoid following a negative trajectory. They also were able to transform their behavior and recognize that they fundamentally had to make a change in how they behave and respond. As one youth's family member noted, "They now have a sense of volunteerism and are initiating the things that they will do" (EDC, 2019c, p. 21).

Promoting agency and contribution through engagement builds a solid foundation for transformative resilience capacities. Toward this end, MYDev established youth networks (YNs) and YDAs. YNs select their leaders and develop youth-led activities. YDAs are a multi-sectoral partnership for collaboration that includes youth leaders, local government, the private sector, and other key stakeholders that facilitate youth empowerment through opportunities and engagement.

In short, both YNs and YDAs worked together to increase youth awareness of their role within their community, facilitating interaction among the groups and with community and government leaders. As demonstrated by the quasi-experimental study, encouraging youth to be part of the 


\section{Resilience-Informed Positive Youth Development}

YN and engage in community service activities, the MYDev program may have helped improve youth's perceptions of their communities (EDC, 2019b). The ability to contribute to something bigger than oneself is a critical resilience-builder, especially because it affects not just the individual or family, but also the surrounding community and environment. As noted in the outcome harvest study:

MYDev's contribution to youth's increased resilience is not only present in the content of the trainings, but in creating the spaces and opportunities, throughout all of its trainings, for youth to interact with each other and resolve conflict or disagreement in a positive way, develop their self-confidence, and their sense of belonging. (EDC, 2019c, p. 11)

This resilience-informed PYD approach led to incremental gains in mutual trust among youth, the community, and the government, which served to rebuild healthier, more cohesive communities. Youth's increased feelings of belonging can be interpreted as a proxy for strengthening the social contract between local government and the community (EDC, 2019b). In short, through a resilience-informed PYD approach focused on the individual and the community, youth are actively absorbing and adapting and further strengthening their enabling environments. MYDev youth were resilient in the face of the Marawi Siege and were able to take the opportunity to strengthen their assets and agency in order to contribute positively to the development of their peers and the broader community.

\section{IYDA Case Study}

IYDA (2018 - 2021) provides vulnerable youth access to nonformal education pathways via accelerated learning programs (ALPs), professional training centers, and community literacy programs. The project supplemented the basic education program with life skills competencies including communication, leadership, teamwork, and basic business planning.

Building off the success of the MYDev program, the design of IYDA was predicated on the integration of a resilience lens into the PYD framework. The design team addressed the need to support the resilience capacities of youth in North and South Kivu who were facing deprivation from exposure to violent conflict, acute poverty, and limited educational and socio-economic opportunities. Building youth's foundational soft skills and strengthening youth assets correlates directly to developing youth and communities' absorptive resilience capacities. 


\section{Results: IYDA}

Results from IYDA's first cohort studies show that participating youth built a strong sense of self-efficacy, positive identity, and optimism, which contributes to their agency. Data show that $61.9 \%$ of project youth improved their perceived level of self-efficacy, while $56.1 \%$ improved at least one level on their perception of optimism and positive identity (EDC, 2020, p. 2).

Youth also increased their work-readiness and cognitive skills and non-cognitive skills framed by the Big Five Inventory (BFI): $(p<.000)(E D C, 2020, p .46)$. Since the BFI is a diagnostic without benchmarks, IYDA baseline and midline scores were compared to findings from Schmitt et al.'s (2007) data from seven African nations, as shown in Figure 2.

\section{Figure 2. IYDA Youth Scores on Big Five Inventory ${ }^{3}$}

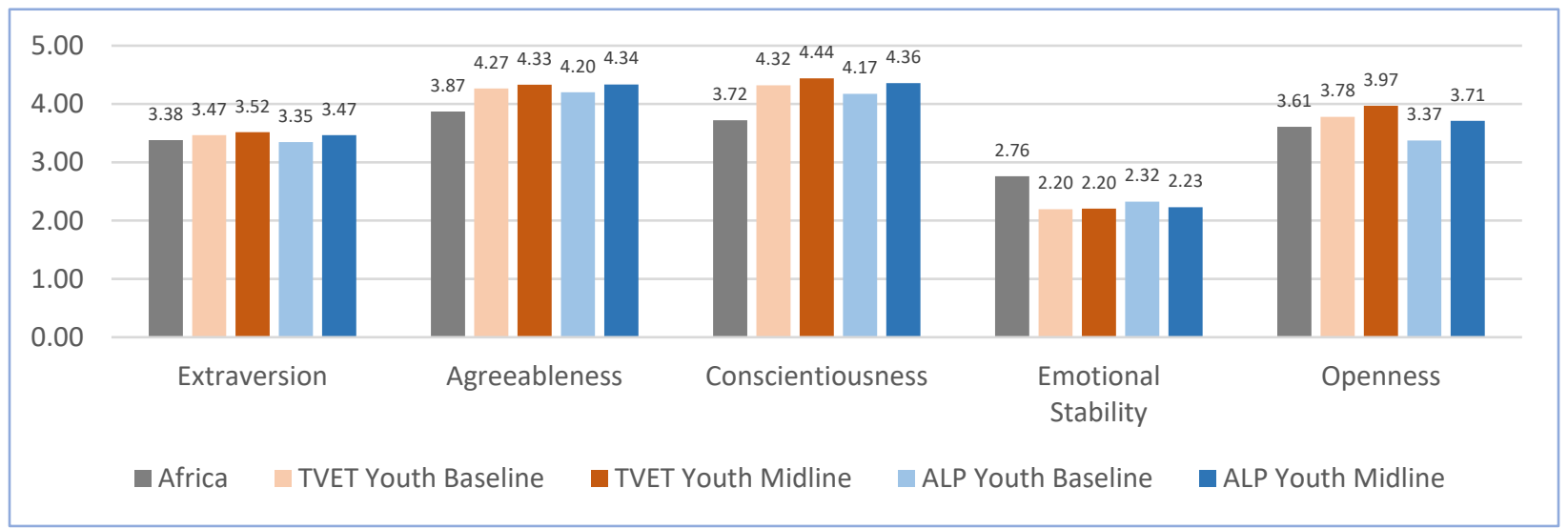

Overall, $60.3 \%$ of IYDA's Cohort I youth improved their work-readiness soft skills at midline (EDC, 2020, p. 50). While BFI results are subject to self-score bias, midline data suggest an increase in work ethic, teamwork, analytical thinking, emotional intelligence, and confidence-all of which contribute to agency and resilience in the face of volatility and instability.

The impact of youth's civic engagement activities is also demonstrably positive. At baseline, $22.1 \%$ of the youth surveyed had participated in a civil society association in their community at midline, this increased to $36.3 \%(p<.001)$ (EDC, 2020, p. 16). Midline results also showed a

\footnotetext{
${ }^{3}$ On the dimension of emotional stability, ALP youth scored themselves lower at the midline compared to the baseline and TVET youth. With the positive correlation of these results with perception of school safety-which is lower than TVET youth-these results may highlight a higher sense of awareness of emotional stability within their surroundings noting a need for continued support towards building safer learning environments for ALP youth.
} 


\section{Resilience-Informed Positive Youth Development}

significant increase in youth's self-esteem and self-image; $54.4 \%$ of youth improved their perception of their roles as leaders solving the problems of the community (EDC, 2020, p. 21). The most notable change was a $14 \%$ increase from baseline in responding positively to the statement, "In my community, young people understand their role as important partners of the leaders solving the problems of the community" (EDC, 2020, p. 18). This finding is complemented by data indicating that $57.4 \%$ of youth improved their self-perception of not engaging in violence, a trend that is interpreted to illustrate greater adaptive and transformative capacities (EDC, 2020, p. 29) that affect both individual and community resilience.

\section{IYDA Discussion}

For more than two decades, the eastern Democratic Republic of Congo has endured a complex protracted emergency. An estimated 120 armed groups clash regularly, and youth have grown up in a context where violence and displacement are normalized. Most youth have insufficient access to public services, including education and health. Like many conflict-affected youth, IYDA participants are among the least likely to understand how to leverage positive coping mechanisms to survive and thrive. With limited access to the social safety nets that support positive coping strategies at both the institutional level (e.g., education, social services) and the community level (shared trust and values among individuals, and between groups), youth are at risk of exhausting their meager resilience capacities for even mild stressors.

IYDA promotes youth agency through interventions focused on goal setting, self-control, selfesteem, and technical skills development. Participants employ foundational soft skills and pursue work-based learning, vocational skills training, or entrepreneurship. These are the same competencies that contribute to adaptive resilience capacity, aiding youth to identify and manage risks through foresight, planning, and bolstered response and recovery mechanisms. IYDA helps channel individual and group energy to set and achieve goals and pivot when necessary. For example, in the early months of COVID-19, many IYDA participants recognized an opportunity and responded quickly with small business ventures, selling masks and operating hand-washing stations.

IYDA participants benefit from a network of volunteers as part of their learning and livelihood supports. Literacy volunteers offer tutoring and homework support. Business mentors accompany youth pursuing a work-based learning opportunity or an entrepreneurship pathway. Students are guided in setting and realizing short-, medium-, and long-term goals. This in turn 


\section{Resilience-Informed Positive Youth Development}

provides new opportunities to build youth agency and contribution and create a bank of socioeconomic support resources.

IYDA participants are encouraged to engage in community service projects and civic engagement. Youth lead a community-mapping exercise to engage stakeholders in identifying and prioritizing community needs. Youth then are provided with technical and material support to implement agreed-on activities, thus positioning youth as promising community resources. In addition to the $54.4 \%$ of youth who improved their leadership self-perception, in solving community-level problems (EDC, 2020, p. 18), anecdotal evidence indicates that participating in these activities helped youth develop the confidence needed to build social networks, selfmotivation, and risk-tolerance to set and achieve personal and community goals. Through this combined academic and practical approach, youth develop an enabling environment leveraging new opportunities to repair the social fabric and reinforce cohesion. In other words, they are building their transformative resilience capacities as they strengthen the enabling environment.

We know that safe learning environments directly contribute to communities' and systems' transformative resilience capacities. In the Democratic Republic of Congo, teachers, volunteers, and mentors are also affected by trauma and are often unable to attend to their own mental health needs, let alone those of their students. Data from a survey conducted midway through the IYDA project indicate that only $48 \%$ of teachers reported knowing how to control their anger, worry, or sad feelings when required. Even fewer (42\%) reported believing that they can talk about a student's abuse or traumatic experience in a way that helps and does not harm the student. Overall, $41.5 \%$ of the teachers surveyed believed that their own experiences with violence still affect them, and $18 \%$ reported losing control, yelling, or using physical aggression against a student (EDC, 2019a).

To address these issues, IYDA developed a resilience-building curriculum designed for nonclinical education staff that focused on core cognitive-behavioral responses to violence at school. Teachers assessed their behaviors and then learned stress management and coping skills to respond in a healthier way to daily difficulties. While impact measurement of the teacher training on youth well-being was disrupted by COVID-19 school closures, post-training assessments showed significant knowledge improvements among the participating teachers. The enabling environment is strengthened by better-equipped child and youth protection actors serving crisis- and conflict-affected populations. 


\section{Resilience-Informed Positive Youth Development}

\section{Conclusion}

These case studies demonstrate how contextually appropriate resilience-informed PYD programming in the Democratic Republic of Congo and the Philippines responded effectively to the complex ebb and flow of emerging stability and development. This integrated approach allowed participants to better master and apply assets, agency, and community contributions in their efforts to cope with adversity.

The addition of a resilience lens to PYD programs is significant for both programs and participants. Since PYD and resilience programs include similar activities (social-emotional skill building and community engagement), the added resilience focus allows for a more carefully tailored sequence of activities to adapt and respond to shocks and stressors, whether in evolving from a humanitarian to a development context, or from a development setting to an emergency. This explicit acknowledgement of participants' contextual challenges can produce concrete strategies to address drivers of crises, building a foundation of understanding and agency to serve beyond the program.

Below we offer recommendations based on MYDev and IYDA program strategies that support applying a resilience lens to PYD programs and identify possible entry points to leverage and maximize impact.

\section{Recommendation 1: Soft Skills Programs Must be Contextually Appropriate and Risk-Informed}

Soft skills development should be grounded in an understanding of individual and communitylevel risk and resilience, and thus will enable individuals, communities, and local organizations to absorb, adapt, and if possible, transform, despite shocks and stressors. A combination of resilience-informed soft skills, supportive community relationships, and safe spaces can best prepare youth to cope with crisis and conflict.

Resilience-oriented soft skills training programs that are anchored in a PYD framework should include activities that demonstrate positive models of preparedness and response, networking and social cohesion. These programs should include a foundation of basic education and soft skills to support youth in establishing a solid footing for learning and growth. Interpersonal, leadership, and decision-making skills provide a critical foundation for youth to engage meaningfully and productively in society, simultaneously contributing to their absorptive and 


\section{Resilience-Informed Positive Youth Development}

adaptive resilience capacities. This effectively equips youth to face daily challenges, learn from past trauma and violence, and feel supported by their peers and community.

Finally, youth programs can benefit greatly not only from including these approaches in vocational or educational training curricula, but also in creating safe and supportive spaces for youth to practice their newly acquired soft skills with one another and in their communities.

\section{Recommendation 2: Strengthen Community Capacity by Investing in Youth Civic Engagement}

Investing in youth agency and civic engagement strengthens both youth and community resilience capacities - their ability to $a b s o r b$ and adapt in the face of adversity.

As demonstrated in the two case studies, resilience-focused PYD programming helped youth take ownership of their own development and contribute to their communities in resilienceenhancing ways-despite broken trust and fragile systems depleted by conflict and crisis. Possible resilience access points for future programs include youth-led crisis risk assessment and preparedness, peer support and coaching, and youth-led peace-building activities. Programs should start with the assumption that youth have a range of valuable skills and that applying a resilience-informed PYD approach enhances and expands individual and community development.

Civic engagement can be an effective mechanism for strengthening individual resilience and community cohesion and can lay the groundwork for transformation. Contributing to something bigger than oneself is often a critical resilience lever, especially because it can enhance wellbeing-not just of the individual or family, but also of the surrounding community and environment. Furthermore, resilience-informed civic engagement can be an effective mechanism for re-engaging youth in positive roles and for changing the perceptions, behaviors, and attitudes of all parties involved. Even in challenging contexts, youth volunteers can shape their communities, thus improving the perception of youth as potential positive actors of change.

\section{Recommendation 3: Promote Social Cohesion Through Resilience-Informed PYD}

In crisis and conflict affected environments, social cohesion is frequently challenged or nonexistent. A resilience-informed PYD approach to programming can enhance an awareness of the drivers of social tension and grievance and can help vulnerable youth access learning and 
Journal of Youth Development | http://jyd.pitt.edu/ | Vol. 16 Issue 2-3 DOI 10.5195/jyd.2021.1020

\section{Resilience-Informed Positive Youth Development}

livelihood opportunities and health services. Activities that help youth strengthen their own agency, create and foster positive bonds within their communities, and contribute to the protection of life and livelihood as part of a community are critical. Indeed, transformative capacity can be built through systems-strengthening, with youth engaged as participants in and contributors to both peace-building and development.

\section{References}

Alvarado, G., Skinner, M., Plaut, D., Moss, C., Kapungu, C., \& Reavley, N. (2017). A systematic review of Positive Youth Development programs in low- and middle-income countries. YouthPower Learning, Making Cents International.

https://www.youthpower.org/sites/default/files/YouthPower/files/resources/SystematicReview FINAL 9-26-17 compress.pdf

Béné, C., Wood, R. G., Newsham, A., \& Davies, M. (2012). Resilience: New utopia or new tyranny? Reflection about the potentials and limits of the concept of resilience in relation to vulnerability reduction programmes. IDS Working Papers.

https://onlinelibrary.wiley.com/doi/abs/10.1111/j.2040-0209.2012.00405.x

Bronfenbrenner, U. (1977). Toward an experimental ecology of human development. American Psychologist, 32(7), 513-531.

Casey, K., \& Pottebaum, D. (2017). Youth and violent extremism in Mindanao, Philippines: Testing assumptions about drivers of extremism -What matters most? Philippines Enhancing Governance, Accountability, and Engagement (ENGAGE) Project.

Education Development Center, Inc. (2019a). DRC integrated youth development activity (IYDA) summary report: Training first cohort of educators on the module "Supporting the resilience of educators" from December 18-20, 2019.

Education Development Center, Inc. (2019b). USAID's Mindanao youth for development (MYDev) program. FY17 impact evaluation report \& FY18/19 (extension) performance evaluation report. https://www.edc.org/sites/default/files/uploads/MYDev\%20Impact\%20Eval Master FINAL.pdf

Education Development Center, Inc. (2019c). USAID's Mindanao youth for development program. Increasing youth's resilience to violence. https://pdf.usaid.gov/pdf docs/PA00W5Q1.pdf

Education Development Center, Inc. (2020). USAID/DRC integrated youth development activity (IYDA) cohort I midline outcome evaluation report.

EU Science Hub. (2020, November 20). Humanitarian crises around the world are becoming longer and more complex. https://ec.europa.eu/jrc/en/news/humanitarian-crises-around-world-arebecoming-longer-and-more-complex 
Journal of Youth Development | http://jyd.pitt.edu/ | Vol. 16 Issue 2-3 DOI 10.5195/jyd.2021.1020

Resilience-Informed Positive Youth Development

Jessee, C., Kapungu, C., \& Brady, K. (2019). Examples of positive youth development program activities aligned with PYD features, mapped to a socio-ecological model. YouthPower Learning, Making Cents International.

https://www.youthpower.org/sites/default/files/YouthPower/files/resources/PYD\%20Features\%2 OMatrix final\%208.2019.pdf

Kadir, A., Shenoda, S., Goldhagen, J., Pitterman, S., \& and Section on International Child Health. (2018, December). The effects of armed conflict on children. Pediatrics, 142(6), e20182586. https://doi.org/10.1542/peds.2018-2586

Keck, M., \& Sakdapolrak, P. (2013).What is social resilience? Lessons learned and ways forward. Erdkunde, 671), 5-19. https://doi.org/10.2307/23595352

Lerner, R. M. (2006, December). Resilience as an attribute of the developmental system. Resilience in Children, 1094(1), 40-51.

Masten, A. S. (2014). Invited commentary: Resilience and positive youth development frameworks in developmental science. Journal of Youth and Adolescence, 43, 1020. https://doi.org/10.1007/s10964-014-0118-7

McCandless, E., \& Simpson, G. (2015, June 15). Assessing resilience for peacebuilding. executive summary of discussion document. Interpeace. https://www.interpeace.org/wpcontent/uploads/2015/09/2015 0911 FAR-Executive-Summary-2015-v3.pdf

Panter-Brick, C., \& Eggerman, M. (2012). Understanding culture, resilience, and mental health: The production of hope. https://doi.org/10.1007/978-1-4614-0586-3 29

Schmitt, D. P., Allik, J., McCrae, R. R., \& Benet-Martínez, V. (2007). The geographic distribution of big five personality traits: Patterns and profiles of human self-description across 56 nations. Journal of Cross-Cultural Psychology, 38(2), 173-212. https://doi.org/10.1177/0022022106297299

Shah, R. (2019). Transforming systems in times of adversity: Education and resilience. USAID Education in Crisis and Conflict Network.

https://www.eccnetwork.net/sites/default/files/media/file/101219\%20Resilience\%20in\%20Educa tion\%20White\%20Paper\%20-\%20Final_0.pdf

Simpson, G. (2018). The missing peace: Independent progress study on youth, peace and security. UNFPA and PBSO. www.youth4peace.info/ProgressStudy

Ungar, M. (2013). Resilience, trauma, context, and culture. Trauma, Violence, \& Abuse, 14(3), 255-266. https://doi.org/10.1177/1524838013487805

USAID. (2012). Policy and program guidance on building resilience to recurrent crisis. https://www.usaid.gov/sites/default/files/documents/1866/Policy\%20\%26\%20Program\%20Guida nce\%20-\%20Building\%20Resilience\%20to\%20Recurrent\%20Crisis Dec\%202012.pdf 
Journal of Youth Development | http://jyd.pitt.edu/ | Vol. 16 Issue 2-3 DOI 10.5195/jyd.2021.1020

\section{Resilience-Informed Positive Youth Development}

Wilson-Grau, R., \& Britt, H. (2012). Outcome harvesting. Ford Foundation. https://outcomeharvesting.net/outcome-harvesting-brief/

YouthPower. (n.d.-a). Positive youth development (PYD) framework.

https://www.youthpower.org/positive-youth-development-pyd-framework

YouthPower. (n.d.-b). What is positive youth development? https://www.youthpower.org/positive-youthdevelopment 